\title{
Hereditary sensorimotor neuropathy with hyperelastic skin
}

INSERM

\section{Source}

INSERM. (1999). Orphanet: an online rare disease and orphan drug data base. Hereditary sensorimotor neuropathy with hyperelastic skin. ORPHA:280598

Hereditary sensorimotor neuropathy with hyperelastic skin is a rare, genetic, demyelinating hereditary motor and sensory neuropathy disorder characterized by slowly progressive, mild to moderate, distal muscle weakness and atrophy of the upper and lower limbs and variable distal sensory impairment, associated with variable hyperextensible skin and age-related macular degeneration. Hypermobility of distal joints, high palate, and minor skeletal abnormalities (e.g. pectus excavatus, dolichocephaly) may also be associated. 